rapidly increased in amount and importance, and the laboratories and staff have been greatly extended in recent years. It is obvious that in the wide sense the scientific investigation of raw materials provides an enormous field, and it was necessary to limit the work of the department to those materials which are considered to be of most importance from a commercial point of view and are best dealt with in this country, and also to a large extent to limit the scientific investigation of these selected materials to the subjects requiring elucidation from the commercial viewpoint. Even with these necessary limitations a large number of scientific papers have been communicated by the staff of the department to the Royal Society, Chemical Society, Society of Chemical Industry, and other societies, whilst a number of materials of promise in scientific research have been passed for investigation to workers in other institutions, including the Universities of Manchester, Liverpool, Leeds, Aberdeen, and London.

To the research laboratories, which are provided with the proper equipment for experimental research, have been added testing plant and machinery for enabling small-scale technical trials of certain raw materials to be carried out. Arrangements have also been made with manufacturers for trials on a commercial scale of materials which appear to be suitable for commercial employment, and the department is now utilised not only for such investigations as have been indicated, but by manufacturers and merchants in this country for obtaining information as to supplies of raw materials, their nature and com position, and also as to their uses and the means of overcoming technical difficulties in regard to their industrial employment.

The scientific results of investigation conducted by members. of the staff are, as a rule, communicated to the special societies concerned, whilst records of some of the principal results obtained in their commercial bearings are printed in the quarterly Bulletin of the Imperial Institute.

THE LISTER INSTITUTE OF PREVENTIVE $M E D I C I N E$.

THE institute originated from a public meeting 1 summoned by the Lord Mayor in July, 1889, to hear statements from scientific men as to the efficacy of Pasteur's treatment for hydrophobia. The lack of any institute in this country with objects similar to those of the Institut Pasteur in Paris was discussed, and it was pointed out that England should continue to take her share in the discovery of means to control disease and not be dependent upon the national laboratories of France and Germany.

A committee was formed, of which Lister became chairman, and in 1891 the British Institute of Preventive Medicine was founded.

During the first nine years of its existence the permanent income of the institute was hopelessly inadequate to the requirements, but in 1900 it received a gift of $250,000 l$. from Lord Iveagh, which for the first time placed it in possession of an assured income. In 1903 the title of Lister Institute was adopted.

The central institute is situated on the banks of the Thames at Chelsea. It contains laboratories equipped for the study of bacteriology, biochemistry, protozoology, experimental pathology, entomology, etc., and a library and theatre. These accommodate, in addition to the staff, 20-30 graduates who are engaged in researches in some subject pertaining to preventive medicine under the guidance of the staff. The institute is a school of the University of London, and graduates of any university may proceed to the degree of doctor of science after having satisfactorily NO. $26 \mathrm{IO}$, VOL. IO4] conducted during two years a research under the direc. tion of a member of the staff who is a recognised teacher in the University.

In addition to its central laboratories in London the institute has a branch where antitoxic sera, bacterial vaccines, and calf-vaccine lymph are manufactured, and where investigations into the improvement of these curative and prophylactic agents, their standardisation, etc., are carried out.

The institute is administered by a governing body of seven, upon which the Earl of Iveagh has three representatives and the Royal Society one. The remaining three are elected by the members.

The income of the institute is derived from two sources, about one-third from endowment and the remainder partly from the sale of antitoxins, etc., and partly from moneys received from Government Departments and municipal authorities as remunera. tion for investigations and diagnoses carried out at their request.

THE NATIONAL PHYSICAL LABORATORY.

I F fifty years ago a Government had proposed to allocate $5_{50}$, oool. per annum for the furtherance of scientific research, it would have met with an unsympathetic response in Parliament, and in all prob. ability would have been turned out of office as too visionary and unpractical. The growth of the belief in the influence of research on industry and com. merce was slow in this country, and was due, perhaps, more to the successful application to the production of electricity and of light of the laws of electromagnetic induction discovered by Faraday than to any other fact. When Dr. (now Sir Oliver) Lodge urged the necessity of a National Physical Laboratory in his address to the Mathematical and Physical Sec. tion of the British Association in 1891, Berlin and Paris had already taken action. A committee of the association, under the chairmanship of Sir Douglas Galton, drew up a scheme for the foundation of such a laboratory, and, after a favourable report by a Treasury Committee under Lord Rayleigh appointed to consider the matter, the laboratory was founded in I90I, with Dr. (now Sir Richard) Glazebrook as director and an annual income of 50ool. The control was vested in the council of the Royal Society, who appointed an executive committee. Owing to the rapid growth of the work of the laboratory, the financial responsibility became too great for the Royal Society, and the financial control was taken over by the Government in I9I8. So well has the laboratory justified its foundation that the Government is pre. pared not only to make the annual grant mentioned in the opening sentence, but also to support a Depart. ment of Scientific and Industrial Research, and National Chemical and Engineering Laboratories are not outside the bounds of possibility.

\section{THE DAVY FARADAY RESEARCH LABORATORY OF THE ROYAL INSTITUTION.}

THE Davy Faraday Research Laboratory of the Royal Institution was founded and endowed by the late Dr. Ludwig Mond, F.R.S., with the object of providing opportunity for original investigation to extend knowledge in the domain of pure chemical and physical science by persons (men and women of any nationality) who could satisfy the authorities of the laboratory of their scientific training and qualifications to conduct original research.

The laboratory was opened on December 22, 1896 , by his Majesty King Edward VII., who took 